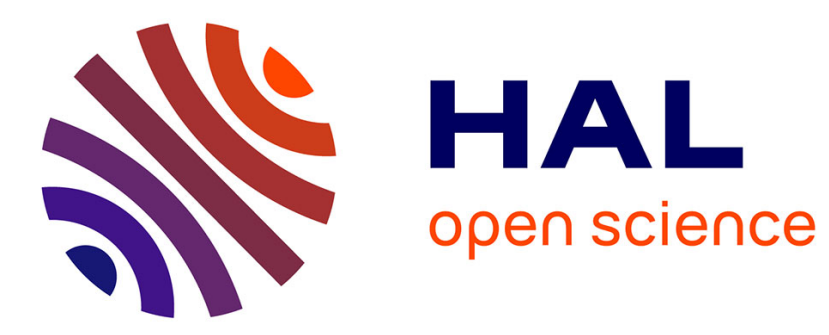

\title{
Water in clay nanopores
}

Benjamin Rotenberg

\section{To cite this version:}

Benjamin Rotenberg. Water in clay nanopores. MRS Bulletin, 2014, Water at Functional Interfaces, 39 (12), pp.1074-1081. 10.1557/mrs.2014.251 . hal-01491121

\section{HAL Id: hal-01491121 https: / hal.sorbonne-universite.fr/hal-01491121}

Submitted on 21 Nov 2018

HAL is a multi-disciplinary open access archive for the deposit and dissemination of scientific research documents, whether they are published or not. The documents may come from teaching and research institutions in France or abroad, or from public or private research centers.
L'archive ouverte pluridisciplinaire HAL, est destinée au dépôt et à la diffusion de documents scientifiques de niveau recherche, publiés ou non, émanant des établissements d'enseignement et de recherche français ou étrangers, des laboratoires publics ou privés. 


\section{Water in clay nanopores}

Benjamin Rotenberg

Clay minerals are layered magnesium or aluminum silicates, which are abundant in Earth's crust. Used since ancient times for the fabrication of bricks or terracotta, they now find application in the pharmaceutical and plastics industries. They play an essential role in oil and gas recovery, in water availability, and in preventing the dissemination of pollutants. In all of these contexts, the relevant properties of clay minerals are intimately linked to their microscopic structure, which results in a rich behavior with respect to water, solutes, and other fluids. This article provides a brief overview of the structure, dynamics, thermodynamics, and reactivity of water in clays, highlighting the role of the various types of water-mineral interfaces. Based on recent experimental and simulation studies, we discuss several features of these interfacial materials arising from their interactions with water on the molecular scale, including swelling, wetting, hydrodynamics in clay nanopores, reactivity of clay edge sites, ion exchange, and sorption.

Keywords: Water, ion exchange material, simulation.

\section{Introduction}

Clay minerals derive from the weathering of minerals formed deep in Earth's crust. They are rich in aluminum and silicon and contribute significantly to the crust mass. They are characterized by a lamellar structure and dimensions smaller than a micron, giving rise to a large specific surface area and, for some of them, to swelling and ion exchange in the presence of water. ${ }^{1}$ Dispersed in water, clay minerals display colloidal behavior, as they are subject to thermal motion because of their small size. The properties of clay minerals led to their use by humans, long before there was any understanding of the underlying processes, for a variety of applications including components in the fabrication of bricks, tiles, terracotta, earthenware, and porcelain; texturizing agent in paints; fillers in paper and plastics; and cat litter. They are also used as catalysts in the pharmaceutical 
industry, as additives in drilling fluids in the oil industry, and even as a medicine in the treatment of acute gastroenteritis.

Because of their abundance in soils and underground and their various properties, clay minerals are also involved in a number of processes in the environment. They can act as water "reservoirs," filled by rain or irrigation, that provide water during droughts. Their ability to sorb traces of both inorganic and organic pollutants also plays an important role in the containment of soil pollution. Clay-rich geological formations are usually very tight, exhibiting a low permeability to fluids. They are found as hard, resistant caprocks above natural gas or sequestered $\mathrm{CO}_{2}$ reservoirs, preventing the rise of buoyant fluids toward the surface. ${ }^{2}$ On the contrary, overcoming this low permeability is the goal of hydraulic fracturing to extract oil or gas from shales. ${ }^{3}$ The combination of mechanical, hydraulic, and sorption performances makes them efficient barriers against the transport of fluids and solutes. Several countries are therefore considering clay-rich geological formations, possibly with clays as buffer and backfill materials as well, for the disposal of high-level and long-lived radioactive waste. $^{4}$

The breadth of applications listed above is made possible thanks to the variety of physicochemical properties of clay minerals, arising from their microscopic structure and resulting in rich behavior with respect to water, solutes, and other fluids. This article provides a brief overview of the structure, dynamics, thermodynamics, and reactivity of water in clays, highlighting the role of the various types of water-mineral interfaces in these materials. In the following sections, we first introduce the structure of clay minerals. We then discuss several features of these interfacial materials arising from the interplay between clay minerals and water, including swelling, wetting, hydrodynamics in clay nanopores, reactivity of clay edge sites, ion exchange, and sorption.

\section{Clay structure}

Clay minerals belong to the family of aluminosilicates and encompass a wide range of chemical compositions and (to a lesser extent) structures. ${ }^{1}$ Unlike zeolites, which form three-dimensional crystals, clay minerals have a layered 
structure. Each layer consists of two to four sheets of tetrahedral (T) silicon oxide and octahedral $(\mathrm{O})$ aluminum or magnesium oxide (Figure 1). O-terminated layers, as in kaolinite, are covered with hydroxyl $(\mathrm{OH})$ groups, whereas Tterminated layers, such as the TOT members on which we focus here, display siloxane rings with hexagonal cavities in which hydroxyl groups from the $\mathrm{O}$ sheet are buried. In dioctahedral clays such as pyrophyllite, two-thirds of the octahedral sites are occupied by $\mathrm{Al}^{3+}$ ions, whereas in trioctahedral clays such as talc, all of these sites are occupied by $\mathrm{Mg}^{2+}$ ions. The $\mathrm{OH}$ groups are then oriented approximately parallel and perpendicular to the sheets, respectively, in the two types of clays. In some cases, particularly in synthetic clays, the $\mathrm{OH}$ groups are replaced by $\mathrm{F}^{-}$ions.

The assembly of parallel layers forms stacks called clay particles (Figure 2). In most clay minerals, some cations are substituted by others with lower valency: $\mathrm{Si}^{4+}$ by $\mathrm{Al}^{3+}$ in the $\mathrm{T}$ layer; $\mathrm{Al}^{3+}$ by $\mathrm{Mg}^{2+}$ or $\mathrm{Fe}^{2+}$ and $\mathrm{Mg}^{2+}$ by $\mathrm{Li}^{+}$in the $\mathrm{O}$ layer. The mineral layer is then negatively charged, and this charge is compensated by counterions between layers, typically $\mathrm{Na}^{+}, \mathrm{K}^{+}$, or $\mathrm{Ca}^{2+}$ under natural conditions, in the so-called interlayer porosity (Figure 2a). Depending on the charge density of the layer and the nature of the counterions, both of which are controlled by the geochemical composition during the formation of the minerals, the interlayer cations can be hydrated in the presence of water, resulting in an increase in the interlayer distance (swelling), and/or be exchanged by other cations (ion exchange).

These particles are finite, with dimensions that largely depend on the nature of the clay. Typically, the number of layers is a few tens, and the lateral extension is a few hundreds of nanometers, with specific areas on the order of $10-10^{3} \mathrm{~m}^{2} / \mathrm{g}$. In addition, these layers are usually not perfectly aligned, so that the concept of clay particle can be ambiguous and the small coherence length renders the resolution of their atomic structure by x-ray diffraction a challenging task. Nevertheless, it is clear that there are, in addition to the above-mentioned interlayer porosity, some additional pores with sizes from a few nanometers to a few hundreds of nanometers, referred to as interparticle pores (Figure $2 b$ ), 
through which fluids can flow. The lamellar structure further results in different types of surfaces: basal surfaces along the layers and lateral surfaces presenting different chemical moieties (as they result from the termination of the mineral layers) and providing access for water and solutes into the interlayer.

\section{Water in clay interlayers}

We first consider the case of interlayer water and discuss the thermodynamics of clay swelling, which results from the entrance of water into the interlayer. The extreme confinement down to the molecular scale results in unusual structural and dynamical properties.

\section{Swelling}

The water content in clay interlayers depends on the nature of the clay and the type of counterion, as well as the thermodynamic conditions (pressure, temperature, relative humidity $[\mathrm{RH}]) .{ }^{5,6}$ For $\mathrm{RH} \approx 0 \%$, the interlayer contains no or very few water molecules. With increasing $\mathrm{RH}$, water uptake first proceeds stepwise, as does the interlayer distance measured by $\mathrm{x}$-ray diffraction (Figure 3a-b). ${ }^{7}$ For $\mathrm{RH} \approx 100 \%$, this discrete crystalline swelling regime is followed by a more continuous one (osmotic swelling).

Whereas illite, a highly charged clay with $\mathrm{K}^{+}$counterions, exhibits no swelling, smectite clays such as montmorillonite (dioctahedral) and saponite (trioctahedral) with $\mathrm{Na}^{+}$counterions can exist with no (dry), one (monolayer), two (bilayer), or even three water layers, with increases in the interlayer distance occurring in steps corresponding to the size of a water molecule. Figure $3 \mathrm{c}$ shows that, for a given number of water layers and a given counterion, the mass of water per unit cell and the interlayer distance depend on the surface charge density, the localization of the charge in the $\mathrm{T}$ (saponite) or $\mathrm{O}$ (hectorite) sheets, and the replacement of $\mathrm{OH}$ by $\mathrm{F}$ in the O-terminated layers. ${ }^{8}$

The equilibrium distance is determined by the balance between the mechanical pressure exerted on the layers and the swelling pressure induced by the hydration of interlayer counterions. Under given thermodynamic conditions, several hydration states (e.g., mono- and bilayer) might be metastable and coexist 
in various proportions. Such metastability is also at the origin of the hysteresis observed during adsorption/desorption cycles (see Figure 3a). Significant progress in the understanding of swelling thermodynamics and the underlying microscopic mechanisms was achieved thanks to molecular simulations, ${ }^{9-18}$ in particular, grand-canonical Monte Carlo (GCMC) simulations. These simulations not only allowed the determination of the swelling free energies ${ }^{19}$ and mechanical properties of clays as functions of the interlayer water content ${ }^{20}$ but also provided insights into the microscopic interlayer structure.

\section{Structure and dynamics of interlayer water}

The structure and dynamics of water in clay layers can be probed experimentally using $\mathrm{x}$-ray and neutron diffraction and using quasi-elastic neutron scattering (QENS), respectively. Combined with molecular simulations, these techniques provide a detailed picture of the interlayer properties. Figure $4 \mathrm{a}$ illustrates the interlayer structure of Na-saponite in the bilayer state. ${ }^{21}$ The density profiles of $\mathrm{Na}^{+}, \mathrm{O}$, and $\mathrm{H}$ in the direction perpendicular to the surface obtained by classical molecular simulations clearly support the bilayer picture, with two maxima for $\mathrm{O}$ atoms. $\mathrm{OH}$ bonds are found mainly parallel to or approximately perpendicular to the surface, whereas $\mathrm{Na}^{+}$cations are found either fully solvated in the center of the pore or partially desolvated near the surface. This figure also shows the signal predicted from these density profiles for x-ray diffraction (reflecting the electronic density, i.e., mainly $\mathrm{O}$ atoms), as well as neutron diffraction experiments using normal and deuterated water (both mainly reflecting the positions of $\mathrm{H}$ atoms). The agreement is remarkable and simultaneously confirms the validity of the model used in the molecular simulations (a modified version of the most commonly used CLAYFF model ${ }^{22}$ ) and the interpretation of the experimental data.

Figure $4 \mathrm{~b}$ similarly shows the signal measured by QENS for the same system, in the direction perpendicular to the clay layer, and the predictions of molecular dynamics (MD) simulations - once more in good agreement. The motion of water confined in the interlayer is highly anisotropic. ${ }^{23,24}$ In addition, the water diffusion coefficient deduced from these results is smaller than that in 
bulk water, to an extent that depends on the hydration state and on the nature of the counterion. For example, in Na-montmorillonite, it decreases by factors of $\sim 5$ in the bilayer state and $\sim 10$ in the monolayer state, whereas for Csmontmorillonite in the monolayer state, water diffusion is slowed by a factor of $20 .^{25,26}$ Here again, molecular simulations have allowed some clarification of the microscopic mechanisms at play. ${ }^{27-32}$

\section{Water in interparticle pores}

We now turn to the case of water in interparticle pores. Such pores can be sufficiently large, with dimensions ranging from a few to a few hundred nanometers, to allow for hydrodynamic flows to develop. Transport is nevertheless limited by the smallest pore throats, for which interfacial effects play an essential role. We introduce first the structure and dynamics of water on basal surfaces, before turning to the impact of this surface water on the hydrodynamic flow in interparticle nanopores. This progression brings us naturally to the wetting properties of clay surfaces, which we discuss in the particular case of neutral clays such as talc.

\section{Water at basal surfaces}

Basal surfaces of clay particles are flat over distances much larger than molecular sizes. As a result, water on basal surfaces adopts a layered structure.

Figure 5b illustrates the density profiles obtained from molecular simulations of water and ions in a 4-nm-wide pore between Na- (Cs-) montmorillonite surfaces containing a $1 \mathrm{M}$ solution of $\mathrm{NaCl}(\mathrm{CsCl})$, depicted in Figure 5a. The strong oscillations near the surface reveal the layering of water over a distance approximately $1 \mathrm{~nm}$ from the surface. ${ }^{33} \mathrm{Cl}^{-}$anions are repelled from the negatively charged clay surface, whereas cations can form surface complexes that depend on the nature of the cation. Figure 5c shows typical structures of innersphere complexes (ISCs) and outer-sphere complexes (OSCs). In the former case, some surface $\mathrm{O}$ atoms participate in the first solvation shell of the cation, thereby resulting in a shorter distance of the ion from the surface (most $\mathrm{Cs}^{+}$ions, see Figure 5b); in the latter case, the ion remains fully solvated (most $\mathrm{Na}^{+}$ions). ${ }^{34,35}$ 
Molecular simulations have further allowed the detailed investigation of the structure and dynamics of surface hydrogen-bond networks. ${ }^{33,36}$ In the first adsorbed layer, approximately half of the water molecules donate H-bonds to surface $\mathrm{O}$ atoms. The remaining water molecules donate one or two H-bonds to these surface-bonded molecules (see Figure $5 \mathrm{~d}$ ). The diffusion of water molecules along the surface is slowed compared to that in the bulk. Regarding the orientational order and dynamics of the water dipole, only the component normal to the clay surface is perturbed. Similar findings have been reported for other lamellar oxides and hydroxides. ${ }^{37-40}$

\section{Hydrodynamics in interparticle pores}

For practical applications, one generally considers the transport of fluids through a porous material such as clays within an effective medium theory, wherein the fluid flux is linked to the macroscopic pressure gradient through the permeability of the sample (Darcy's law). This macroscopic law can be recovered, from the theoretical point of view, by upscaling the classical laws of hydrodynamics (Navier-Stokes) from the pore scale to the scale of the sample, either numerically or by numerical homogenization. ${ }^{41}$ However, these continuous descriptions might not be valid in pores with sizes comparable to the molecular size. $^{42}$

Figure 6 illustrates how nonequilibrium molecular dynamics (NEMD) simulations allow for the investigation of the flow of fluids through such nanopores, by applying a force on the fluid mimicking the effect of a pressure gradient. In this simple slit geometry, continuous hydrodynamics predicts a parabolic velocity profile (Poiseuille flow). Despite the layering of surface water, which results in a more complex flow in the vicinity of the walls, the velocity profile more than $1.5 \mathrm{~nm}$ away from the surface is well described by the NavierStokes equation, with a viscosity equal to that of bulk water. It is necessary, however, to take into account slip boundary conditions at the clay-solution interface by introducing a slip length determined from molecular simulation. ${ }^{43}$ This length is very small (less than the size of a water molecule for Namontmorillonite), but its effects on the overall flow through the pore can be large 
for nanometer-sized pores. ${ }^{44}$ Such hydrodynamic slip is related to the hydrophilic/hydrophobic balance of clay surfaces, in particular, whether they are charged or neutral. ${ }^{45}$

\section{Wettability of talc and related clay minerals}

The wetting properties of soils and rocks play an important role in the transport, and hence the availability, of water and hydrocarbons. In charged clays, the presence of counterions favors the presence of water on basal surfaces. On the contrary, the surface of neutral TOT clays, covered with siloxane rings, is generally hydrophobic (see Figure 1). For example, the contact angle of water droplets on pyrophyllite or talc monocrystals is large $\left(80-90^{\circ}\right)$. Such hydrophobic behavior, consistent with the above-mentioned slip, is well reproduced by molecular simulations with the CLAYFF force field, ${ }^{22}$ which predicts similar contact angles for talc, fluorotalc, and pyrophyllite (Figure 7a). ${ }^{46}$ In the case of talc, this contrasts with the presence of highly hydrophilic sites leading to the adsorption of water vapor, with a Gibbs free energy of adsorption of $\sim 30 \mathrm{~kJ} / \mathrm{mol}$, consistent with the formation of a H-bond with a surface hydroxyl group. Such Hbonds cannot form in the case of fluorotalc, and as a result, this mineral does not adsorb water at low $\mathrm{RH}^{47}$

This dual macroscopic hydrophobicity and microscopic hydrophilicity might seem surprising. In fact, by means of an analysis of the competition between water-surface and water-water interactions based on molecular simulations, ${ }^{46}$ it was shown that there is no contradiction between these two regimes. At low $\mathrm{RH}$, the adsorption free energy for an isolated water molecule displays a strong minimum for talc above the hexagonal siloxane cavities (Figure $7 b$ ), confirming the presence of a H-bond donated by the surface hydroxyl group. The adsorption is much weaker on pyrophyllite and fluorotalc, in which these groups are parallel to the surface and absent, respectively. At low RH, the surface coverage by water results from a balance between the adsorption energy and the favorable entropy of water in the gas phase. At high RH, water molecules interact more strongly with each other (cohesion) than with the surface (adhesion), so that the adsorption sites are empty, even in the case of talc. 


\section{Water at clay edges}

Finally, we discuss the last type of clay surface, namely, lateral surfaces. As already mentioned, these surfaces provide the only access into and out of the interlayer. They are therefore essential for swelling and ion exchange. In addition, clay edges display chemical moieties different from those on the basal surfaces that can react chemically with water and provide sorption sites for cations.

\section{Water and ion exchange via edges}

One of the most important processes governing cation retention by clays is cation exchange between ions in solution and interlayer counterions, through lateral surfaces. The exchange of interlayer $\mathrm{Na}^{+}$counterions by $\mathrm{Cs}^{+}$in solution is thermodynamically favorable (negative reaction free energy, $\Delta_{\mathrm{r}} G$ ) and exothermic (negative reaction enthalpy, $\Delta_{\mathrm{r}} H$ ). The consensus of thought was that this exchange resulted from favorable interactions between the $\mathrm{Cs}^{+}$cations and the clay surface. This point of view was challenged by Teppen and Miller, ${ }^{48}$ who used molecular simulations to compute the free energy associated with the replacement of $\mathrm{Na}^{+}$by larger alkaline cations and found that, in fact, the interactions with the clay surface contribute unfavorably to the exchange. The overall exchange is thermodynamically favorable only because of the replacement of $\mathrm{Cs}^{+}$by $\mathrm{Na}^{+}$in the aqueous phase, that is, because of the difference in hydration free energy between the two ions. This finding underlines the essential role of water in ion exchange. Similar conclusions were drawn for the reaction enthalpy, including its evolution with interlayer water content, by combining molecular simulations with microcalorimetry experiments. ${ }^{49}$ Molecular simulations further provided the first study of the exchange process on the microscopic scale, using the system illustrated in Figure 8a. It was found that, for Na-montmorillonite in the bilayer state, water and cations can exchange via the edges with no or small activation barriers, whereas anions are excluded from the interlayer. ${ }^{50}$ As the interlayer distance increases, the entrance of anions can become possible. ${ }^{51}$

\section{Acidity of edge sites}


The finite extent of clay particles results in the breaking of chemical bonds, mainly $\mathrm{Si}-\mathrm{O}$ and $\mathrm{Al}-\mathrm{O}$ bonds. Unsaturated surface atoms then react with water molecules, resulting in new chemical moieties. For example, the (010) faces of pyrophyllite and montmorillonite display aluminol sites, $\mathrm{AlOH}$ and $\mathrm{AlOH}_{2}$, and silanol sites, $\mathrm{SiOH}$ (Figure 8a). These sites can (de)protonate and play an important role in the sorption of ions, in particular, multivalent cations in the context of radioactive waste disposal. One should then be able to predict the protonation states of the various sites as functions of $\mathrm{pH}$. This requires knowledge of the $\mathrm{p} K_{\mathrm{a}}$ value of each site, which is related to the reaction free energy for the transfer of the surface proton to a water molecule. For example, for a silanol group, the transfer reaction is written as

$$
-\mathrm{SiOH}+\mathrm{H}_{2} \mathrm{O}(\mathrm{aq}) \rightarrow-\mathrm{SiO}^{-}+\mathrm{H}_{3} \mathrm{O}(\mathrm{aq})^{+} .
$$

Experimentally, titration experiments provide only a global picture of the surface, not a local picture of the state of each site. ${ }^{52}$ One must then resort to $a$ priori or experimental information in structure-based models such as MUSIC ${ }^{53}$ to reproduce the titration curve. ${ }^{54}$ Water near such surface edge sites can also be investigated using ab initio molecular dynamics (AIMD) simulations based on density functional theory (DFT), which capture the possible breaking and formation of chemical bonds. Figure $8 \mathrm{~b}$ illustrates a proton-transfer event between an $\mathrm{AlOH}_{2}$ site and an $\mathrm{AlOH}$ site on the (010) face of pyrophyllite, mediated by two surface water molecules. ${ }^{55}$

By combining AIMD with specific techniques (e.g., thermodynamic integration), it is possible to compute the free energy associated with the deprotonation reaction in Equation 1, as well as two other quantities relevant to the thermodynamics of this process: the vertical energy gap, $\Delta E_{\mathrm{AH}}$, and the reorganization free energy, $\Delta F$ (Figure $8 \mathrm{c}$ ). $\mathrm{SiOH}$ is slightly more acidic than $\mathrm{AlOH}_{2}$, with $\mathrm{p} K_{\mathrm{a}}$ values close to 7 for both sites, whereas $\mathrm{AlOH}$ does not deprotonate in water $\left(\mathrm{p} K_{\mathrm{a}} \approx 22\right)$. The reorganization free energy, arising from bond-length relaxation and solvent reorganization after deprotonation, cannot be neglected. For example, the strong stabilization of $\mathrm{SiO}^{-}$after deprotonation is explained by the arrival of two water molecules donating H-bonds. ${ }^{56}$ This further 
illustrates the importance of water on clay edges. The presence of substitutions inside the mineral layer also plays a role in the acidity of neighboring edge sites. ${ }^{57}$

\section{Conclusions and outlook}

Clay minerals display various types of surfaces associated with a range of exciting properties with respect to water. Whereas swelling involves interlayer nanopores, fluid flow through clays can also proceed through interparticle pores, thereby experiencing the influence of basal and lateral surfaces. The molecular aspects discussed herein play an essential role in the thermodynamics and transport of fluids and solutes, with measurable effects on the macroscopic scale. Important efforts are thus devoted to upscaling the relevant features from the molecular scale to the sample scale. ${ }^{41}$

Nevertheless, there is still plenty of room for improvement even at the bottom. From the experimental point of view, characterizing the threedimensional structure on the mesoscopic scale remains a challenge and should benefit from the latest developments in imaging techniques such as x-ray microscopy. ${ }^{58}$ On a more microscopic scale, $x$-ray reflectivity has already provided new results on the interface between mica (a highly charged clay mineral) and aqueous solutions, suggesting that surface relaxation of the solid might extend over a few mineral layers. ${ }^{59}$ From the modeling point of view, it would be desirable to improve the force fields used in molecular simulations to account for water polarization and its changes at the interface, in particular, for the sorption of multivalent ions.

Finally, although the present work discusses only water and small inorganic ions at clay surfaces, it is important to mention that other solutes such as organic molecules and other fluids (e.g., $\mathrm{CO}_{2}$ and $\mathrm{CH}_{4}$ ) remain much less studied on the molecular scale. ${ }^{60-63}$ Such compounds also play important roles in various contexts ranging from pollutant sorption to the possible catalytic role of clay minerals in the origin of life, and from $\mathrm{CO}_{2}$ sequestration to shale gas extraction. In addition, the properties of water on clay surfaces could provide useful concepts for other nanoporous materials, such as zeolites and metalorganic frameworks. 


\section{Acknowledgments}

The author is grateful to the many students and colleagues who have contributed to this work over the past 10 years, in particular, Alexandru Botan, Sami Tazi, Virgnie Marry, Mathieu Salanne, and Pierre Turq, as well as overseas collaborators, in particular, Amish J. Patel and D. Chandler.

\section{References}

1. F. Bergaya, G. Lagaly, Eds., Handbook of Clay Science (Elsevier, Oxford, UK, 2006).

2. I. Gaus, Int. J. Greenhouse Gas Control 4, 73 (2010).

3. G.E. King, paper presented at the SPE Hydraulic Fracturing Technology Conference, The Woodlands, TX, 6-8 February 2012 paper SPE 152596.

4. P. Delage, Y.J. Cui, A.M. Tang, J. Rock Mech. Geotech. Eng. 2, 111 (2010).

5. J.M. Cases, I. Bérend, M. François, J.P. Uriot, J.E. Poirier, Langmuir 8, 2730 (1992).

6. I. Bérend, J.M. Cases, M. François, J.P. Uriot, L.J. Michot, A. Masion, F. Thomas, Clays Clay Miner. 43, 324 (1995).

7. N. Malikova, A. Cadène, E. Dubois, V. Marry, S. Durand-Vidal, P. Turq, J. Breu, S. Longeville, J.-M. Zanotti, J. Phys. Chem. C 111, 17603 (2007).

8. B. Dazas, B. Lanson, J. Breu, J.-L. Robert, M. Pelletier, E. Ferrage, Microporous Mesoporous Mater. 181, 233 (2013).

9. N. Skipper, K. Refson, J. McConnell, Clay Miner. 24, 411 (1989).

10. A. Delville, J. Phys. Chem. 97, 9703 (1993).

11. N. Skipper, F.-R. Chang, G. Sposito, Clays Clay Miner. 43, 285 (1995).

12. E.S. Boek, P.V. Coveney, N.T. Skipper, J. Am. Chem. Soc. 117, 12608 (1995).

13. E.S. Boek, P.V. Coveney, N.T. Skipper, Langmuir 11, 4629 (1995).

14. D. Young, D. Smith, J. Phys. Chem. B 104, 9163 (2000).

15. E.J.M. Hensen, B. Smit, J. Phys. Chem B 106, 12664 (2002).

16. E.S. Boek, M. Sprik, J. Phys. Chem B 107, 3251 (2003). 
17. T. Tambach, P. Bolhuis, B. Smit, Angew. Chem. Int. Ed. 43, 2650 (2004).

18. X.-D. Liu, X.-C. Lu, Angew. Chem. Int. Ed. 45, 6300 (2006).

19. H.D. Whitley, D.E. Smith J. Chem. Phys. 120, 5387 (2004).

20. B. Carrier, M. Vandamme, R.J.M. Pellenq, H. Van Damme, J. Phys. Chem. C 118, 8933 (2014).

21. E. Ferrage, B. Sakharov, L.J. Michot, A. Delville, A. Bauer, B. Lanson, S. Grangeon, G. Frapper, M. Jiménez-Ruiz, G. Cuello, J. Phys. Chem. C 115, 1867 (2011).

22. R.T. Cygan, J.J. Liang, A.G. Kalinichev, J. Phys. Chem. B 108, 1255 (2004).

23. N. Malikova, S. Longeville, J.-M. Zanotti, E. Dubois, V. Marry, P. Turq, J. Ollivier, Phys. Rev. Lett. 101, 265901 (2008).

24. L.J. Michot, E. Ferrage, M. Jiménez-Ruiz, M. Boehm, A. Delville, J. Phys. Chem. C 116, 16619 (2012).

25. V. Marry, P. Turq, T. Cartailler, D. Levesque, J. Chem. Phys. 117, 3454 (2002).

26. V. Marry, P. Turq, J. Phys. Chem. B 107, 1832 (2003).

27. N. Malikova, V. Marry, J.F. Dufrêche, P. Turq, Curr. Opin. Colloid Interface Sci. 9, 124 (2004).

28. B. Rotenberg, V. Marry, J.-F. Dufrêche, N. Malikova, E. Giffaut, P. Turq, C.R. Chim. 10, 1108 (2007).

29. P.C. Morrow, A.Ö. Yazaydin, M. Krishnan, G.M. Bowers, A.G. Kalinichev, R.J. Kirkpatrick, J. Phys. Chem. C 117, 5172 (2013).

30. M. Holmboe, I.C. Bourg, J. Phys. Chem. C 118, 1001 (2014).

31. N. Malikova, E. Dubois, V. Marry, B. Rotenberg, P. Turq, Z. Phys. Chem. 224, 153 (2010).

32. V. Marry, E. Dubois, N. Malikova, S. Durand-Vidal, S. Longeville, J. Breu, Environ. Sci. Technol. 45, 2850 (2011).

33. V. Marry, B. Rotenberg, P. Turq, Phys. Chem. Chem. Phys. 10, 4802 (2008).

34. G. Sposito, R. Prost, Chem. Rev. 82, 553 (1982).

35. G. Sposito, N.T. Skipper, R. Sutton, S.-H. Park, A.K. Soper, J.A. Greathouse, PNAS 96, 3358 (1999). 
36. B. Rotenberg, V. Marry, N. Malikova, P. Turq, J. Phys. Condens. Matter 22, $284114(2010)$.

37. J.W. Wang, A.G. Kalinichev, R.J. Kirkpatrick, Geochim. Cosmochim. Acta 68, 3351 (2004).

38. R.J. Kirkpatrick, A.G. Kalinichev, J.W. Wang, Mineral. Mag. 69, 289 (2005).

39. J.W. Wang, A.G. Kalinichev, R.J. Kirkpatrick, R.T. Cygan, J. Phys. Chem. B 109, 15893 (2005).

40. J.W. Wang, A.G. Kalinichev, R.J. Kirkpatrick, Geochim. Cosmochim. Acta 70, 562 (2006).

41. C. Moyne, M. Murad, Transp. Porous Media 62, 333 (2006).

42. L. Bocquet, E. Charlaix, E, Chem. Soc. Rev. 39, 1073 (2010).

43. J.L. Barrat, L. Bocquet, Phys. Rev. Lett. 82, 4671 (1999).

44. A. Botan, B. Rotenberg, V. Marry, P. Turq, B. Noetinger, J. Phys. Chem. C 115, 16109 (2011).

45. A. Botan, V. Marry, B. Rotenberg, P. Turq, B. Noetinger, J. Phys. Chem. C 117, 978 (2013).

46. B. Rotenberg, A.J. Patel, D. Chandler, J. Am. Chem. Soc. 133, 20521 (2011).

47. L.J. Michot, F. Villiéras, M. François, J. Yvon, R. Le Dred, J.M. Cases, Langmuir 10, 3765 (1994).

48. B.J. Teppen, D.M. Miller, Soil Sci. Soc. Am. J. 70, 31 (2006).

49. B. Rotenberg, J.-P. Morel, V. Marry, P. Turq, N. Morel-Desrosiers, Geochim. Cosmochim. Acta 73, 4034 (2009).

50. B. Rotenberg, V. Marry, R. Vuilleumier, N. Malikova, C. Simon, P. Turq, Geochim. Cosmochim. Acta 71, 5089 (2007).

51. M. Jardat, J.-F. Dufrêche, V. Marry, B. Rotenberg, P. Turq, Phys. Chem. Chem. Phys. 11, 2023 (2009).

52. I.C. Bourg, G. Sposito, A.C.M. Bourg, J. Colloid Interface Sci. 312, 297 (2007).

53. T. Hiemstra, P. Venema, W.H.V. Riemsdijk, J. Colloid Interface Sci. 184, 680 (1996). 
54. C. Tournassat, E. Ferrage, C. Poinsignon, L. Charlet, J. Colloid Interface Sci. 273, 23 (2004).

55. S.V. Churakov, Geochim. Cosmochim. Acta 71, 1130 (2007).

56. S. Tazi, B. Rotenberg, M. Salanne, M. Sprik, M. Sulpizi, Geochim.

Cosmochim. Acta 94, 1 (2012).

57. X. Liu, X. Lu, M. Sprik, J. Cheng, E.J. Meijer, R. Wang, Geochim.

Cosmochim. Acta 117, 180 (2013).

58. S. Brisard, R.S. Chae, I. Bihannic, L.J. Michot, P. Guttmann, J. Thieme, G. Schneider, P.J.M. Monteiro, P. Levitz, Am. Miner. 97, 480 (2012).

59. S.G. Lee, P. Fenter, K.L. Nagy, N.C. Sturchio, Langmuir 28, 8637 (2012).

60. J.A. Greathouse, K.L. Johnson, H.C. Greenwell, Minerals 4, 519 (2014).

61. A. Botan, B. Rotenberg, V. Marry, P. Turq, B. Noetinger, J. Phys. Chem. C 114, 14962 (2010).

62. P. Giesting, S. Guggenheim, A.F. Koster van Groos, A. Busch, Environ. Sci. Technol. 46, 5623 (2012).

63. L.M. Hamm, I.C. Bourg, A.F. Wallace, B. Rotenberg, Rev. Mineral. Geochem. 77, 189 (2013). 

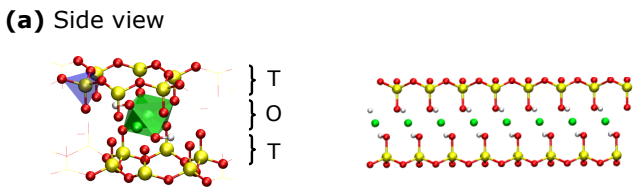

(b) Top view

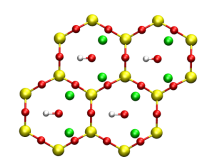

Pyrophyllite

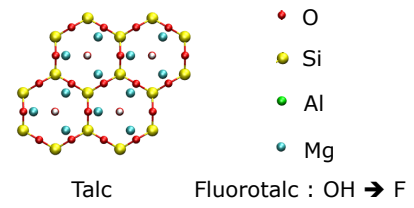

Figure 1. Microscopic structures of clay minerals. (a) Side view of pyrophyllite. Each layer consists of an octahedral aluminum oxide sheet between two tetrahedral silicon oxide sheets. (b) Top views of pyrophyllite and talc, illustrating the hexagonal siloxane rings. In pyrophyllite, two-thirds of octahedral sites are occupied by $\mathrm{Al}^{3+}$, and the hydroxyl $(\mathrm{OH})$ group is along the surface, whereas in talc, all sites are occupied by $\mathrm{Mg}^{2+}$, and the $\mathrm{OH}$ is perpendicular to the surface. In fluorotalc (not shown), the talc $\mathrm{OH}$ groups are replaced by $\mathrm{F}$ atoms. 


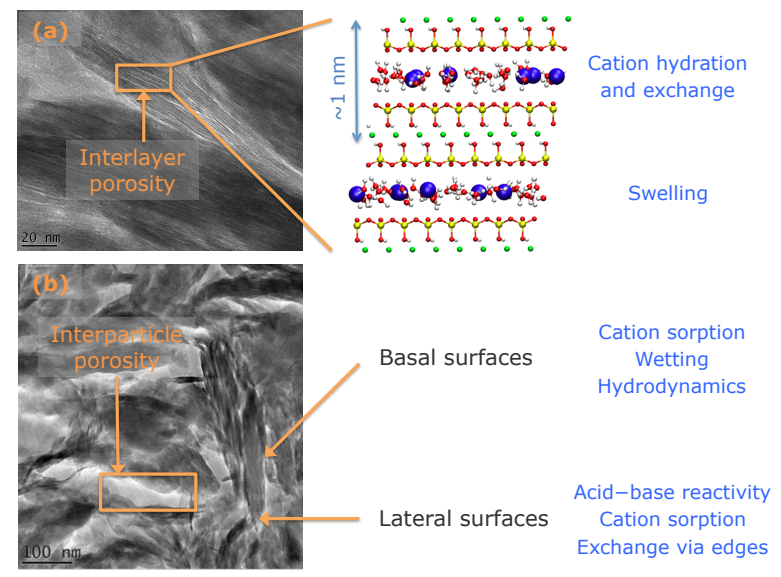

Figure 2. Mesoscopic structure of clay minerals. HRTEM images of Illite du Puy (copyright Stéphane Gaboreau, BRGM). (a) Substitutions in the mineral layer result in a permanent negative charge, compensated by counterions in the interlayer porosity $(<1 \mathrm{~nm})$. In some cases, these cations can be hydrated, resulting in an increase in the interlayer distance (swelling), or be exchanged by other cations in solution. (b) The finite disordered stacking of layers forms socalled clay particles with an associated interparticle porosity. These particles display basal surfaces along the layers and lateral surfaces with different physicochemical properties. 

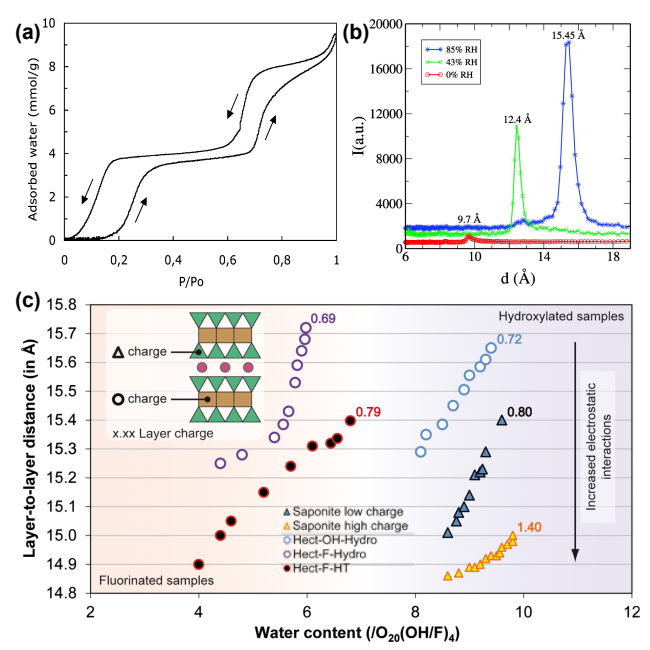

Figure 3. (a) Amount of adsorbed water as a function of relative humidity $\mathrm{RH}=$ $P / P_{0}$ for sodium hectorite at ambient temperature. The water content increases stepwise and hysteresis is observed between adsorption and desorption. (b) x-ray diffraction pattern for the same clay (as a function of interlayer distance $d$ ) for three RH values: The interlayer distance increases in steps of approximately the size of a water molecule. (c) The water content and interlayer distance depend on the surface charge density, the localization of this charge in the $\mathrm{O}$ and $\mathrm{T}$ layers, and the replacement of $\mathrm{OH}$ by $\mathrm{F}$. Figure 3a-b) reproduced with permission from Reference 7. (C) 2007 American Chemical Society. Figure 3c reproduced with permission from Reference 8. (C) 2013 Elsevier. 


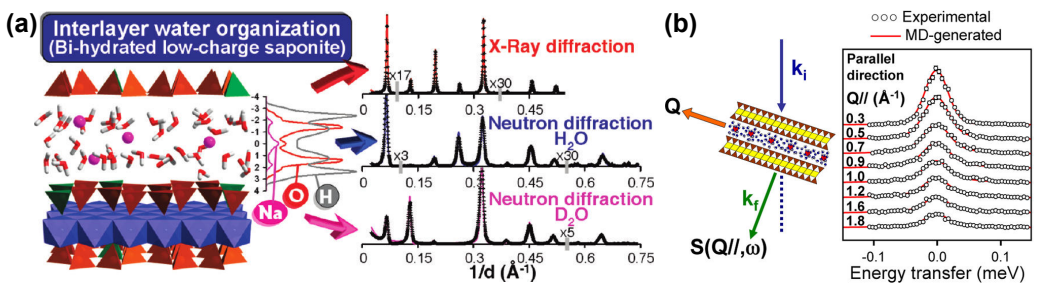

Figure 4. (a) Snapshot of the interlayer of Na-saponite in the bilayer state. The bilayer structure of water is evident in the density profiles from molecular simulations, which can simultaneously reproduce the patterns observed in x-ray and neutron diffraction experiments with both normal and heavy water. (b) Results of quasi-elastic neutron scattering (QENS) experiments used to probe the dynamics of interlayer water. Molecular dynamics (MD) simulations are able to reproduce the experimental signal and provide a microscopic understanding of the anisotropic dynamics of water confined down to the molecular scale. Figure 4a reproduced with permission from Reference 21. (C) 2011 American Chemical Society. Figure 4b reproduced with permission from Reference 24. (C) 2012 American Chemical Society. 


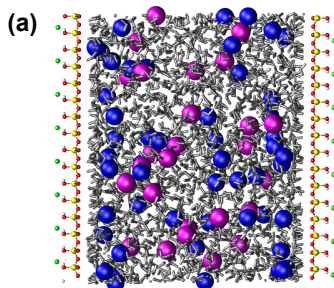

(b) Surface complexes

(c)

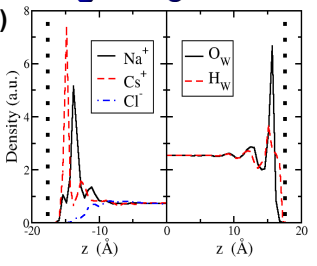

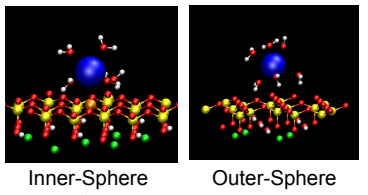

(Most $\mathrm{Cs}^{+}$ions) $\quad$ (Most $\mathrm{Na}^{+}$ions)

(d) Surface H-bond network
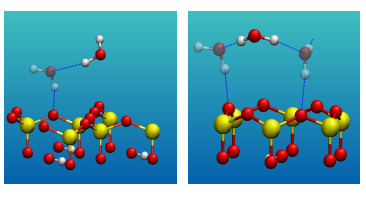

Figure 5. Water on basal surfaces (a) Model of interparticle pore between montmorillonite surfaces used in molecular simulations (blue, $\mathrm{Na}^{+}$; pink, $\mathrm{Cl}^{-}$; gray, water). (b) The density profiles for ions (left) and water (right) reveal the layered structure of the fluid, the sorption of cations and anion exclusion from the negatively charged surface. (c) Surface complexes formed by cations on basal surfaces. (d) The network of hydrogen bonds at the surface involves bonds with the surface and between surface water molecules. Figure $5 \mathrm{a}-\mathrm{c}$ reproduced from Reference 33. (C) 2008 PCCP Owner Societies. 

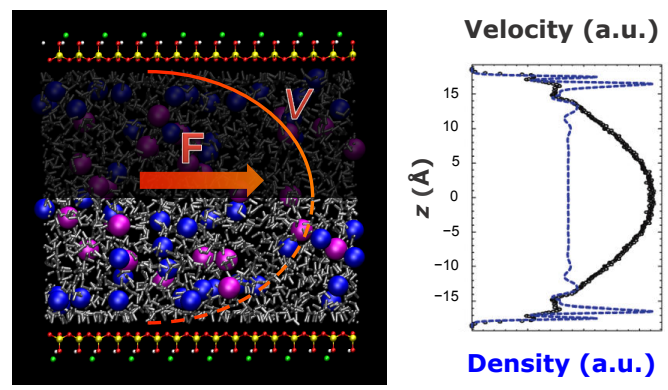

Figure 6. Using nonequilibrium molecular dynamics, it is possible to assess the validity of continuous hydrodynamics. Despite the layered structure of the fluid, the velocity profile far from the surface is well described by the Stokes equation. It is however necessary to introduce slip boundary conditions at the clay-solution interface, with a slip length determined from molecular simulations. Reproduced with permission from Reference 44. (C) 2011 American Chemical Society. 

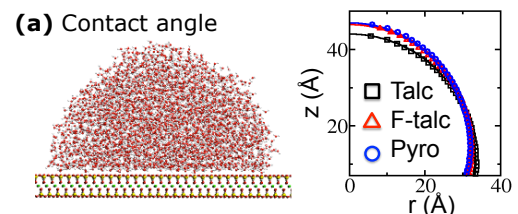

(b) Free energy profile
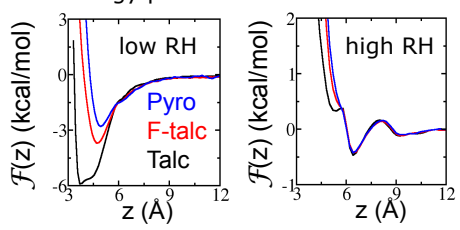

Figure 7. (a) Contact angles of water nanodroplets on talc, fluorotalc, and pyrophyllite, computed from molecular dynamics simulations (left: simulation setup; right: average shape), indicate hydrophobic behavior of the three surfaces. (b) The free energy profile for the adsorption of a single water molecule (left) reflects the presence of strong binding sites in the case of talc, corresponding to the formation of a hydrogen-bond donated by the surface $\mathrm{OH}$ group; binding is much weaker on the other two surfaces. At large relative humidity (right), water interacts more strongly with itself than with the surface and the binding site is empty, even on talc. Reproduced with permission from Reference 46. (C) 2011 American Chemical Society. 


\section{(a)}

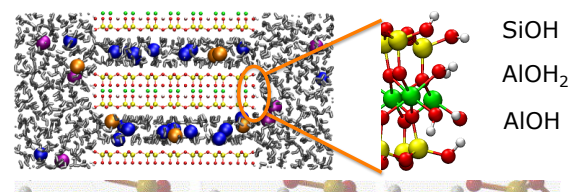

(b)

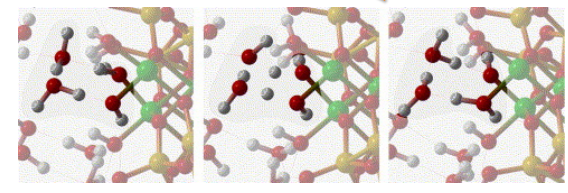

(c)

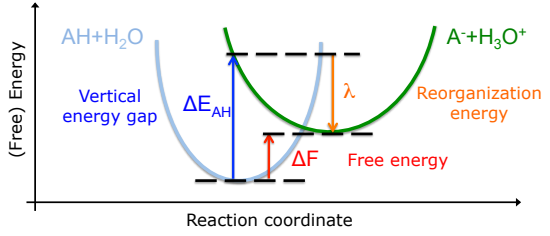

Figure 8. (a) Lateral surfaces provide access to and from the interlayer for water and ions in interparticle pores. Clay edges display sites with moieties different from basal surfaces, such as aluminol and silanol groups on the (010) face of pyrophyllite. Depending on $\mathrm{pH}$, these groups can deprotonate and serve as sorption sites for cations. (b) Proton transfer between surface sites, from $\mathrm{AlOH}_{2}$ to $\mathrm{AlOH}$, by means of a chain of proton transfer through two surface water molecules, from ab initio molecular dynamics (AIMD) simulations. (c) The thermodynamics of the acid-base reaction between surface sites and water molecules can be understood within the framework of the Marcus theory of electron transfer, adapted to proton transfer (Equation 1). Using AIMD simulations, it is then possible to determine the vertical energy gap $\Delta E_{\mathrm{AH}}$, that is, the energy corresponding to proton transfer from the surface to the aqueous phase without reorganization of the site after deprotonation, and the reorganization energy $\lambda$, which arises from changes in bond lengths in the vicinity of the site as well as solvent reorganization after deprotonation. The reaction free energy $\Delta F$, directly related to the $\mathrm{p} K_{\mathrm{a}}$ of the corresponding site, is the sum of these two contributions. ${ }^{55}$ Figure $8 \mathrm{~b}$ Reproduced with permission from Reference 55. (C) 2007 Elsevier. 